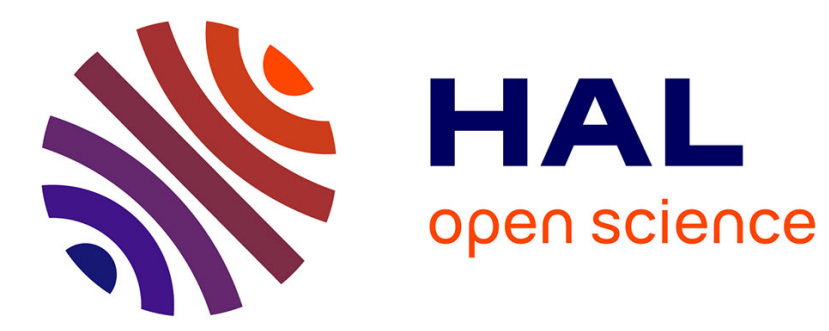

\title{
A geodynamic model of mantle density heterogeneity
}

\author{
Y. Ricard, M. Richards, C. Lithgow-Bertelloni, Y. Le Stunff
}

\section{To cite this version:}

Y. Ricard, M. Richards, C. Lithgow-Bertelloni, Y. Le Stunff. A geodynamic model of mantle density heterogeneity. Journal of Geophysical Research, 1993, 98 (B12), pp.21,895-21,909. 10.1029/93JB02216 . hal-02046765

\section{HAL Id: hal-02046765 https://hal.science/hal-02046765}

Submitted on 3 Feb 2021

HAL is a multi-disciplinary open access archive for the deposit and dissemination of scientific research documents, whether they are published or not. The documents may come from teaching and research institutions in France or abroad, or from public or private research centers.
L'archive ouverte pluridisciplinaire HAL, est destinée au dépôt et à la diffusion de documents scientifiques de niveau recherche, publiés ou non, émanant des établissements d'enseignement et de recherche français ou étrangers, des laboratoires publics ou privés. 


\title{
A Geodynamic Model of Mantle Density Heterogeneity
}

\author{
YANICK RICARD \\ Département Terre-Atmosphère-Océan, Ecole Normale Supérieure, Paris, France \\ MARK RICHARDS ${ }^{1}$ AND CAROLINA LiTHGoW-BERTELLONI ${ }^{1}$ \\ Department of Geology and Geophysics, University of California, Berkeley \\ YVES LE STUNFF ${ }^{2}$ \\ Département Terre-Atmosphère-Océan, Ecole Normale Supérieure, Paris, France
}

\begin{abstract}
Using Cenozoic and Mesozoic plate motion reconstructions, we derive a model of present-day mantle density heterogeneity under the assumption that subducted slabs sink vertically into the mantle. The thermal buoyancy of these slabs is estimated from the observed thermal subsidence (cooling) of oceanic lithosphere. Slab velocities in the upper mantle are computed from the local convergence rate. We assume that slabs cross the upper/lower mantle interface and continue sinking into the lower mantle with a reduced velocity. For a velocity reduction factor between 2 and 5 , our slab heterogeneity model is as correlated witl current tomographic models as these models are correlated with each other. We have also computed a synthetic geoid from our density model. For a viscosity increase of about a factor of 40 from the upper to lower mantle, our model predicts the first 8 spherical hamonic degrees of the geoid with statistical confidence larger than $95 \%$ and explains $84 \%$ of the observed geoid assuming that the model $\mathrm{C} 21$ and S21 terms are absent due to a long relaxation time for Earth's rotational bulge. Otherwise, $73 \%$ of the geoid variance is explained. The viscosity increase is consistent with our velocity reduction factor for slabs entering the lower mantle, since downwelling velocities are expected to scale roughly as the logarithm of viscosity ( $\log _{e} 40=3.7$ ). These results show that the history of plate tectonics can explain the main features of the present-day structure of the mantle. The dynamic topography induced by this heterogeneity structure consists mainly of about 1-km amplitude lows concentrated along the active continental margins of the Pacific basin. Our model can also be used to predict the time variation of mantle heterogeneity and the gravity field. We find that the "age" of the geoid, defined as the time in the past before which the geoid becomes uncorrelated with the present geoid, is about $50 \mathrm{~m} . y$. Our model for the history of the degree 2 geoid, which is equivalent to the history of the inertia tensor, should give us a tool to study the variations in Earth's rotation pole indicated in paleomagnetic studies.
\end{abstract}

\section{INTRODUCTION}

Convection in Earth's mantle gives rise to horizontal density variations which cause lithospheric plate motions at Earth's surface. If the oceanic lithosphere is assumed to be the cold upper boundary layer for global mantle convection, then convection models predict that regions of lithospheric downwelling ("subduction zones") should be underlain by cold descending plumes ("slabs"). If the mantle is heated largely by internal radioactivity, then these downwelling plumes are expected to dominate mantle heterogeneity structure [McK'enzie et al., 1974], with hot upwelling plumes playing a relatively minor role. This basic scenario for mantle dynamics is supported by a broad spectrum of evidence [Davies and Richards, 1992]: Deep WadatiBenioff zone seismicity shows that the lithosphere descends to great depths beneath subduction zones and the large-scale configuration of these subduction zones remains fairly stable in time [Richards and Engetbretson, 1992]. Mid-ocean ridges behave as unstable, passive upwelling features whose

\footnotetext{
'Now at Geophysics Program, University of Washington, Seattle.

${ }^{2}$ Now at Department of Geology and Geophysics, University of California, Berkeley.
}

Copyright 1993 by the American Geophysical Union.

Paper number 93JB02216.

0148-0227/93/93JB-02216\$05.00 thermal signature does not appear to extend deeper than about $100 \mathrm{~km}$ [Zhang and Tanimoto, 1991]. Mantle plumes beneath hotspots, which may arise from the core-mantle boundary [Morgan, 1971], appear to account for only a minor fraction $(\sim 10 \%)$ of Earth's internal heat budget [Davies, 1988a; Sleep, 1991].

Adopting this point of view results in a simple, testable hypothesis: The heterogeneity structure of the mantle should be largely the result of past subduction. The purpose of this paper is to test this hypothesis by constructing a model of mantle heterogeneity based on the history of subduction as revealed by global plate reconstructions for the past $\sim 180$ m.y., i.e., for the Cenozoic and Mesozoic eras. Our approach is in marked contrast with other, observationally based efforts to model mantle heterogeneity, which have relied mainly upon seismic tomography to infer mantle density structure [e.g., Hager et al., 1985; Forte and Peltier, 1987; Ricard et al., 1989; Hager and Richards, 1989; Ricard and Vigny, 1989; Forte et al., 1992]. The main feature that our model has in common with past efforts is that we also attempt to constrain mantle viscosity structure by comparing the observed and predicted gravitational fields [Ricard et al., 1984; Richards and Hager, 1984].

Predicting thermal heterogeneity in the mantle due to subduction is rather straightforward, because of the regular dependence of ocean bathymetry on plate age [Slater and Francheteau, 1970]. This provides a direct measure of the negative plate buoyancy due to cooling and follows log- 
ically from the assumption that the oceanic lithosphere is a thermal boundary layer [e.g., Davies, 1988b]. Hager [1984] used this assumption to derive an excellent fit to the "intermediate" wavelength geoid (spherical harmonic degrees 4-10) based upon the location of subducted slabs in the upper mantle and transition zone revealed by deep seismicity. One of the main conclusions of Hager's study was that there exists a significant increase of viscosity between the upper and lower mantle (a factor of 30-100). However, this upper mantle slab still left unexplained the largest part of the geoid signal, which occurs at harmonic degrees 2-3. This component has subsequently been modeled as arising from lower mantle density structure imaged by seismic body-wave tomography [Dziewonski, 1984; Hager and Clayton, 1989; Tanimoto, 1990; Su and Dziewonski, 1991]. Geodynamic modeling again indicates a viscosity increase from the upper to the lower mantle [Hager et al., 1985].

Following on an earlier suggestion by Chase and Sprowl [1983], Richards and Engetbretson [1992] demonstrated a strong correlation between large-scale lower mantle seismic structure and the time-integrated history of subduction over the past $\sim 120-180$ m.y.: Basically, the deep mantle appears to be cold (high seismic velocity) where subduction has occurred in the past. Interestingly, lower mantle heterogeneity and the geoid are only weakly correlated with the present-day snapshot of subduction zones [Chase, 1979]. This is expected, since subduction zones have evolved considerably during the Cenozoic. For example, both regional [Grand, 1987] and global [Dziewonski, 1984] seismic tomography show high velocity in the lower mantle beneath the North American craton, which is inferred to be the thermal signature of the subducted Farallon plate [Engebretson et al., 1985]. Because most subduction along western North America ceased quite recently, this mantle structure, which is easily explained in terms of past subduction, cannot be predicted from the present-day configuration of subduction zones. Clearly then, a geodynamical interpretation, or prediction, of mantle heterogeneity structure must include the time history of plate tectonics.

Here we take the work of Richards and Engebretson [1992] to its next logical step by using subduction zone reconstructions to create a history of mantle heterogeneity since Mesozoic time. Our model is unique in that we attempt to predict not only the present-day mantle heterogeneity structure but also its evolution in time. Full treatment of the temporal aspects of the model is delayed largely until a future publication. However, the implications may be of considerable interest, since knowing the time evolution of mantle structure allows one to predict, for example, the variations in the planet's moment of inertia ("true polar wander") and global sea level variations (the difference between geoid height and dynamic topography).

In this paper we begin by describing in detail the essential features and assumptions of our mantle heterogeneity model. We then make a systematic comparison between this model and both seismic tomography and the geoid. We are able to achieve an excellent fit to both the geoid and tomography by using a mantle viscosity structure almost identical to that derived in our previous studies. Last, we consider the time variation of mantle heterogeneity structure, and some of its implications.

\section{Mantle Heterogeneity Motel}

We seek to construct a model of mantle heterogeneity based on the assumption that subducted slabs are the primary source of thermal buoyancy in the deep mantle. We further assume that thermal diffusion does not significantly alter the long-wavelength signature of subducted lithosphere on the time scale of interest $(\sim 100-200 \mathrm{~m} . y$.$) . The thermal$ diffusion length scale for mantle rocks is only $\sim 100 \mathrm{~km}$ for a timescale of $100 \mathrm{~m} . y$., i.e., the time it takes to form mature oceanic lithosphere. Since we are interested in modeling mantle heterogeneity at wavelengths of thousands of kilometers (e.g., for modeling global seismic tomography or the satellite geoid), heat diffusion will be negligible for at least a few mantle transit times [Bunge and Richards, 1992].

Thus, rather than solving a full three-dimensional convection problem constrained by plate motions (work in progress), we construct a mechanistic model by invoking a simple parameterisation for the trajectory of subducted slabs. Using a model of past plate motions, we introduce the slabs into the mantle at the position in the hotspot reference frame where they were subducted, at the time they were subducted. Geological time is divided into 5-m.y. intervals, and a slab tracer ("slablet") is assigned for each small amount of plate area subducted along a subduction zone segment during each time interval. These "slablets" become effective point mass tracers that sink through the mantle in a manner described below. To be self-consistent, our model must include all the slabs over a period larger than the characteristic time needed for a slab to sink through the depth of the mantle.

We have used a compilation of the past $200 \mathrm{~m} . \mathrm{y}$. of plate motions compiled by Lithgow-Bertelloni et al. [1993] using various sets of reconstructions [Gordon and Jurdy, 1986; Engebretson et al., 1985, 1992; Scotese, 1992; Minster and Jordan, 1978; Larson and Chase, 1972; Larson and Pitman, 1972]. These reconstructions are similar to those used by Richards and Engebretson [1992]. Models of slab-related heterogeneity computed from these different reconstructions lead to very similar patterns of long-wavelength structure. Within the logic of our model, the early Mesozoic and Paleozoic slabs should be close to the core-mantle boundary or essentially floating on it. It is well known that mass anomalies located close to a chemical interface are locally compensated, thus giving no contribution to the geoid signal or in driving convective motions. These slabs are thus dynamically "dead" although they may influence the coremantle topography or the seismic velocity structure near the core-mantle boundary.

To keep things simple, we suppose that slabs sink vertically in the upper mantle with a velocity equal to the local plate convergence rate. Allowing for a viscosity increase between the upper and lower mantle at a depth of $670 \mathrm{~km}$, we reduce this sinking velocity by a factor less than or equal to the lower/upper mantle viscosity ratio, $\eta_{I} / \eta_{u}$, when the slabs enter the lower mantle. In order to conserve thermal buoyancy, we assume that the slabs are folded or thickened in proportion to this velocity reduction factor.

The appropriate amount of reduction in sinking velocity corresponding to a viscosity increase is questionable. An upper bound would be the viscosity contrast itself $\eta_{l} / \eta_{u}$ assuming that each subducted slablet behaves as as an in- 
dependent Stokesian sinker. On the other hand, studies of steady state convection [Gurnis, 1986] and simple kinematically forced flows [Richards, 1991] with viscous stratification suggest that a more appropriate velocity reduction factor is $\log _{e}\left(\eta_{l} / \eta_{u}\right)$. Using these estimates as upper and lower bounds, we consider a range of slablet velocity reduction of, e.g., 3.4 to 30 for a lower/upper mantle viscosity contrast of 30. However, we expect a value toward the low side of this range based on the numerical simulations cited. In the models we construct, the lower/upper mantle viscosity contrast is the only true free parameter, with the slablet velocity reduction factor restricted to a limited range dependent upon the viscosity contrast.

We also neglect horizontal motions of slabs, consistent with our belief in a significant viscosity increase with depth. The lack of significant horizontal advection of subducted slabs in the lower mantle on the $100 \mathrm{~m} . y$. timescale is also consistent with the very slow relative motion of hotspots [Duncan and Richards, 1991], In this paper, we examine spherical harmonic representations of mass anomalies up to degree 15 , corresponding to half wavelengths greater than $1300 \mathrm{~km}$, so that lateral drift of downgoing slabs by the same amount will not substantially change our results. Therefore, the main source of apparently horizontal slab motion in the mantle is an artifact of trench migration, not deep mantle flow. This results in some inclination of deep slab structure in our model beneath the Americas due to the westward migration of the active continental margins of North and South America since the beginning of the Mesozoic. In contrast, the slabs beneath the western Pacific are more or less vertical in our model due to the remarkable stability of subduction zones in that region through time. Our model also results in some "refraction" of slab trajectories at $670 \mathrm{~km}$ due to the reduction in slablet sinking velocity.

In order to derive a mantle density distribution from our slablets, which represent pieces of subducted plate area, we must assign them an excess surface density $\Delta \sigma$. For the Cenozoic, where we have been able to make age estimates for subducted lithosphere, we use the use the following expression to assign the surface density contrast due to sinking slabs:

$$
\Delta \sigma=80 \mathrm{~kg} / \mathrm{m}^{2} \sqrt{\mathrm{age} / 90},
$$

where the age is in million years. This expression corresponds to $3.5 \mathrm{~km}$ of isostatic thermal subsidence for $90 \mathrm{Ma}$ old oceanic lithosphere, which is roughly equivalent to a lithospheric thickness of $100 \mathrm{~km}$. For the Mesozoic we cannot make reliable subducted plate age estimates, so we assign all Mesozoic slabs an age of $90 \mathrm{Ma}$ in equation (1) above. Again, we neglect thermal diffusion, so we suppose that this excess density remains constant while a slab is sinking. Implicit in this assumption is that the thermal expansivity is inversely proportional to the adiabatic mantle density at any given depth and therefore decreases by a factor of 2 within the mantle. A somewhat higher reduction in thermal expansivity may be more realistic [e.g., Chopelas and Boehler, 1989], but this does not affect our model very much.

Finally, we also neglect variations in crustal and lithospheric thickness at the Earth's surface. These contributions could easily be added a posteriori to improve the uppermost layer of our model (see later discussion).

\section{COMPARISON WITH SEISMIC TOMOGRAPHY}

We compute different present-day distributions of paleoslabs in the mantle according to the velocity reduction factor at $670-\mathrm{km}$ depth. For each velocity reduction factor, the global correlation between the computed 3-D mass anomalies and a global tomographic model is performed. The total correlation $C$ between paleoslabs and mantle tomography can be defined by

$$
C=\frac{\int \sum_{l, m} T_{l m} S_{l m}^{*} r^{2} d r}{\sqrt{\int \sum_{l, m} T_{l m} T_{l m}^{*} r^{2} d r} \sqrt{\int \sum_{l, m} S_{l m} S_{l m}^{*} r^{2} d r}}
$$

where $T_{l m}$ and $S_{l m}$ are the depth dependent harmonic coefficients of the tomography and the slabs, respectively (asterisk denotes the complex conjugate operation). The integrals are performed over the lower mantle since the correlation between our slabs and upper mantle tomography is obviously independent of the velocity reduction factor at $670-\mathrm{km}$ depth. For comparison, we have used the tomographic models SH425.2 [Su and Dziewonski, 1991] and MDLSH [Tanimoto, 1990]. We sum from $l=0$ to $l=6$ since $l=6$ is the maximum harmonic degree present in MDLSH.

Figure 1 shows the global lower mantle correlation between our slabs and SH425.2 as a function of the velocity decrease at $670-\mathrm{km}$ depth. A clear maximum occurs for a slab velocity reduction factor of approximately $s=3$. With MDLSH the best fit is obtained for $\mathrm{s}$ between 4 and 5 , but the maximum correlation is only 0.24 . The dotted line of Figure 1 shows the global correlation, 0.36, between SH425.2 and MDLSH. The disagreement between the two seismic models is larger than the disagreement between our model and SH425.2.

The number of degrees of freedom involved in these comparisons is fairly large. At each depth, the total number of degrees and orders is 48 . Taking the depth resolution of

\section{CORRELATION SLABS/SH425.2}

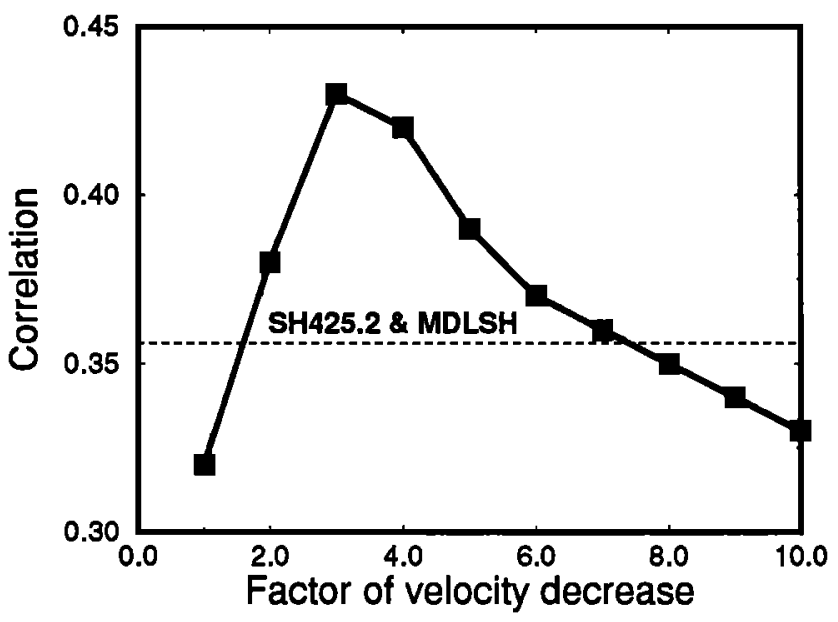

Fig. 1. Global correlation over the lower mantle between the density model deduced from Cenozoic and Mesozoic slabs and the tomographic model SH425.2 [Su and Dziewonski, 1991]. This correlation is maximum when we assume that the slab velocities decrease by a factor 3 at $670 \mathrm{~km}$ depth. The dashed line shows the global correlation between SH425.2 and Tanimoto [1990] tomographic model MDLSH. 
tomography as $500 \mathrm{~km}$, the total number of coefficients has to be further multiplied by a factor of about 5 . We cannot directly identify the total number of degrees of freedom as the total number of spherical harmonic coefficients, since the spectra are not flat. However, we think that the observed correlations between SH425.2, MDLSH, and our model are indeed highly significant. (For example, a correlation of 0.4 is significant at the $95 \%$ confidence level for just 25 degrees of freedom.)

A global degree-by-degree correlation over the lower mantle $C(l)$ can also be computed when the summation in (2) is made only over the orders for each given degree. Figure 2 depicts the results obtained for the first 5 degrees in the comparison of our slab model with SH425.2. Except for degree 1 , each curve has a maximum for a velocity reduction factor of about 2-4. To show the significance of these correlations, the results obtained by comparing the two tomographic models are given on the right side of the graph. For example, they appear to be uncorrelated for $l=4$. At each degree, our slab distribution gives a good fit to each of the tomographic models.

A degree-by-degree correlation $C(l, r)$ between our slabs and tomography can also be computed as a function of depth. We perform this exercise with $s=4.4$, a value which does not give quite the maximum of the correlation, but which we will use later in modeling the geoid. Figure 3 shows that throughout the entire mantle the correlations at degrees 2 and 3 are very high. Degree 1 is also correlated at the bottom and at the top of the lower mantle. In the upper mantle degree 1 appears to be negatively correlated, but amplitudes in both the slab distributions and the tomography are smaller than those of degrees 2 and 3 . The others degrees which are not plotted in Figure 3 are found to be correlated only in the upper one third of the lower mantle, and they are uncorrelated elsewhere.

Even though we find very high correlations, the amplitudes of our density anomalies are different from what is observed by seismology. This amplitude as a function of depth can be characterized by

\section{CORRELATION SLABS/SH425.2}

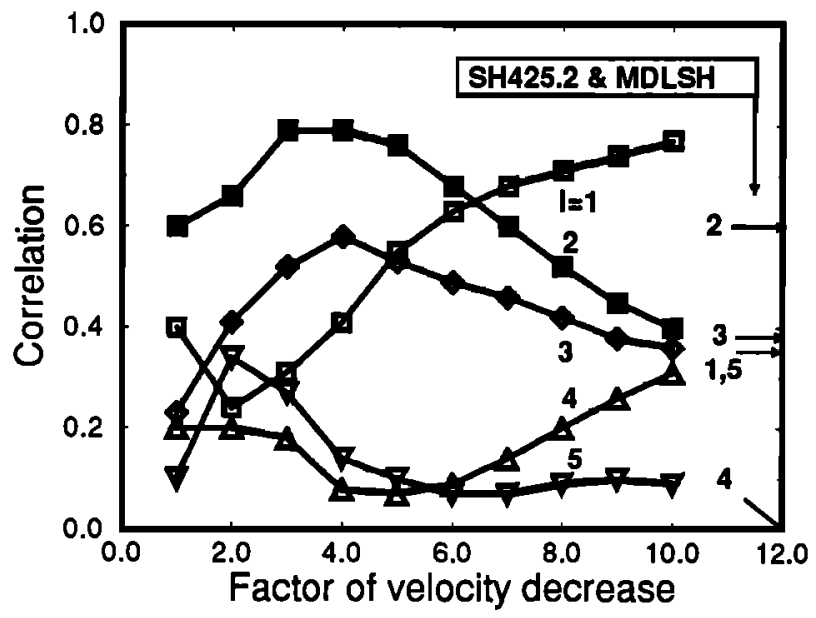

Fig. 2. Degree-by-degree correlations for degices 1 to 5 , over the lower mantle between the slab density model and SH425.2. The degree-by-degree correlations between the two tomographic models SH425.2 and MDLSH are marked along the vertical axis on the right.

\section{CORRELATION SLABS/SH425.2}

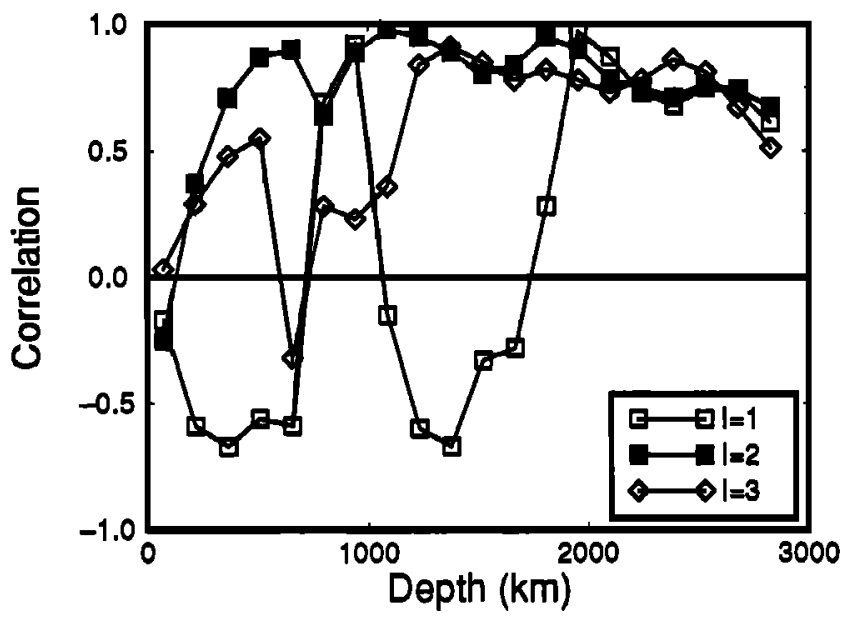

Fig. 3. Radial correlation between the slab density and SH425.2 for the degrees 1, 2, and 3. The slab model has been constructed assuming a velocity decreased by a factor 4.4 at the upper-lower mantle interface.

$$
A=\sqrt{\sum_{l, m} T_{l m} T_{l m}^{*}}
$$

where the summations are performed for degrees $\leq 6$. We have translated the seismic velocity anomalies into density heterogeneities by using a proportionality factor of $0.2 \mathrm{~kg}$ $\mathrm{m}^{-3} / \mathrm{km} \mathrm{s}^{-1}$ throughout the whole mantle depth range. This factor is approximately what is expected on the basis of laboratory experiments [Anderson et al., 1968]. Figure 4 depicts the depth dependent amplitude of $\$ \mathrm{SH} 425.2$ and of our slabs. In the lower mantle the two amplitudes satisfactorily agree when we take into account the large uncertainties in the slab excess density and in the density to velocity ratio. In the upper mantle, slab-related anomalies are a factor of 5 smaller than what is inferred by tomography. Because of the decrease in the sinking velocity by a factor 4 , our anomalies are around 4 times larger in the lower mantle than in the upper mantle. A general increase of amplitude with depth related both to higher activity of the subduction zones in the Mesozoic [Richards and Engebretson, 1992] and to the geometric effect of concentrating masses in a sphere is superimposed on this step like increase.

We know that at least in the top part of the upper mantle the real heterogeneity pattern of the Earth is probably dominated by the mid-ocean ridges, back arc regions, and variations in the thickness of continental lithosphere ("tectosphere"). These seismic velocity variations may result mainly from the effects of partial melting and variations in mantle depletion, which are not included in our model. Their relation to upper mantle density variations is uncertain. In fact, in modeling the long-wavelength geoid using mantle tomography, various authors have decreased the importance of upper mantle sources by ignoring the whole upper mantle [Hager et al., 1985], ignoring the first $400 \mathrm{~km}$ [Forte and Peltier, 1991], or by assuming a low density to velocity ratio [Ricard and Vigny, 1989]. The depth dependent amplitude of Tanimoto's [1990] model is rather comparable to that of SH425.2. However, Montagner and Tanimoto [1991] have derived an upper mantle velocity model that 


\section{SPECTRAL AMPLITUDE}

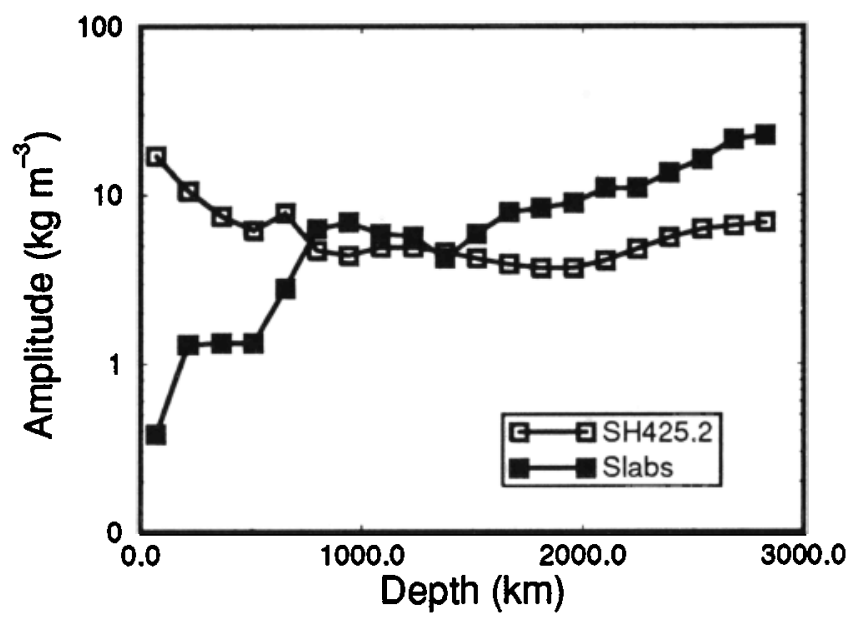

Fig. 4. Density heterogeneity spectra as a function of depth deduced from tomography and from the slab model. The slab model has a much lower amplitude in the upper mantle than what can be deduced from tomography. The two amplitudes are comparable in the lower mantle.

includes anisotropy, with amplitudes decreasing drastically below the depth of $250 \mathrm{~km}$ and comparable with our results in the bottom part of the upper mantle.

The most convincing evidence of the correlation between seismic velocity anomalies and our slab model comes from the direct comparison of anomalies at depth. We examine three different depths 500,1000 , and $2000 \mathrm{~km}$. At each depth, we compute the local distribution of slabs predicted by our model and its expansion in spherical harmonics. We reconstruct the shape of this slab distribution up to degree 15 , then we show the anomaly distribution at degrees 1-3 deduced from the slab model and from $\mathrm{SH} 425.2$. The results are shown in Figures 5,6, and 7. Figures 5a, 6a, and $7 \mathrm{a}$ show the slab distribution up to degree 15 ; Figures $5 \mathrm{~b}, 6 \mathrm{~b}$, and $7 \mathrm{~b}$ show the long-wavelength versions of Figures $5 \mathrm{a}, 6 \mathrm{a}$, and 7a. Figures 5c, 6c, and $7 \mathrm{c}$ show the tomographic results at the same depth. The amplitudes of Figures $5 \mathrm{a}, 6 \mathrm{a}$, and $7 \mathrm{a}$ are normalized so that there are roughly the same number of contour lines. The contour intervals are $2 \mathrm{~kg} / \mathrm{m}^{3}$ apart in Figures $5 c, 6 b, 6 c, 7 b$, and $7 c$. The amplitude of the filtered version of our slab model has been multiplied by 5 in Figure $5 b$ (upper mantle) to balance the difference of amplitude with Figure $5 \mathrm{c}$.

The presence of only Cenozoic slabs gives Figure 5a the well-known pattern of present-day subduction zones. The slabs in Figure 6a were introduced before the breakup of the Philippine plate. The lower mantle slabs of Figure 7a bear the evidence of the northward motion of the Pacific and Kula plates before the Hawaii-Emperor bend. The resemblance between the patterns deduced from our models and from tomography is striking in Figures 6 and 7. The heterogeneities have a sectoral distribution in the midmantle and a zonal one close to the core-mantle boundary.

\section{(GEOID MODELS}

We can now test how well our slab model predicts the present-day gravity field. The computation of a geoid signal from a 3-D density structure can be done by convolving this density structure with a geoid kernel which includes the ef- fects of boundary deformations. The computation of geoid kernels is valid for a model Earth with radially stratified Newtonian viscosity. The effects of lateral viscosity variations [Richards and Hager, 1989; Zhang and Christensen, 1993], compressibility [Forte and Peltier, 1991], and nonlinear rheology [Cadek et al., 1993] are not of prime importance and have been ignored in this paper. We choose the viscosity profile to be as simple as possible. It consists of three layers, a 100-km-thick lithosphere of viscosity $\eta_{l i t h}$, an upper mantle viscosity $\eta_{u}$, and a lower mantle viscosity $\eta_{l}$. The geoid signal is independent of the absolute viscosity so that we take $\eta_{u}=1$.

In recently published papers, the estimated ratio $\eta_{l} / \eta_{u}$ varies considerably. The ratio deduced from postglacial rebound studies was previously estimated to be around 2 [Peltier and Tushingham, 1989]. It is currently found by

\section{SLABS (DEPTH $500 \mathrm{KM}$, DEGREES 1-15)}

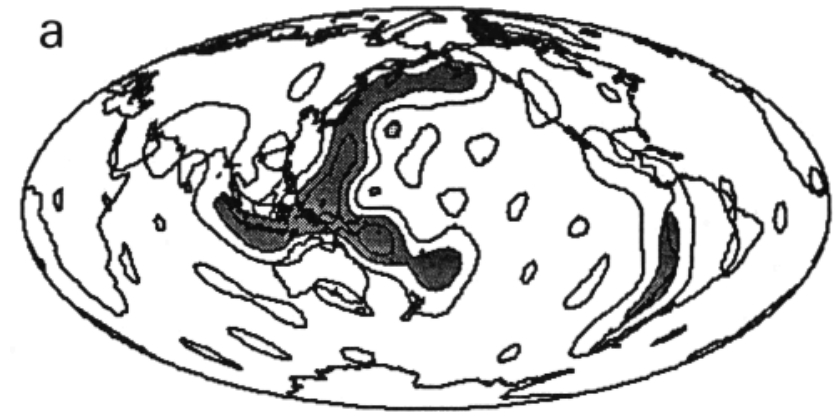

SLABS (DEPTH 500 KM, DEGREES 1-3)

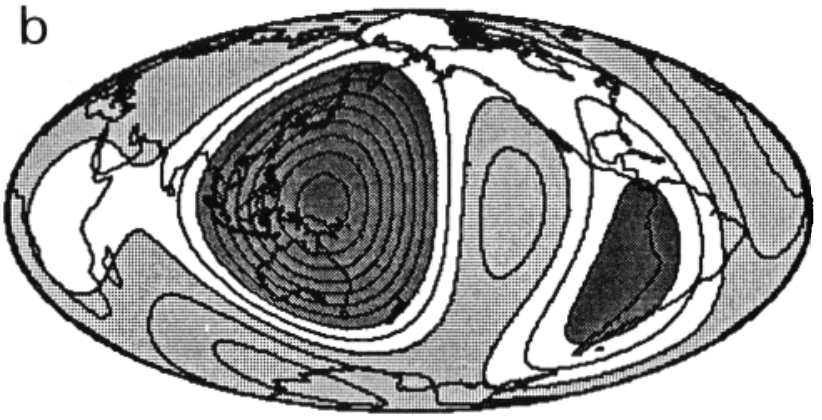

SH425. 2 (DEPTH $500 \mathrm{KM}$, DEGREES 1-3)

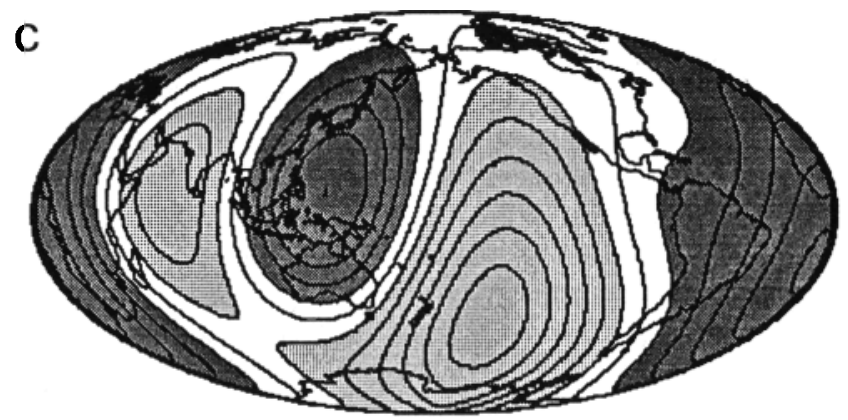

Fig. 5. (a) The slabs inferred from past plate motion at the depth of $500 \mathrm{~km}$. This map has been filtered for degrees larger than 15 . (b) The density variations deduced from Figure 5a when only degrees 1, 2, and 3 are kept. (c) The density variations obtained from SH425.2 at the same degrees and at the same depth. The level lines in Figures $5 \mathrm{~b}$ and $5 \mathrm{c}$ are $0.4 \mathrm{~kg} \mathrm{~m}^{-3}$ and $2.0 \mathrm{~kg} \mathrm{~m}^{-3}$ apart, respectively. 
SLABS (DEPTH $1000 \mathrm{KM}$, DEGREES 1-15)

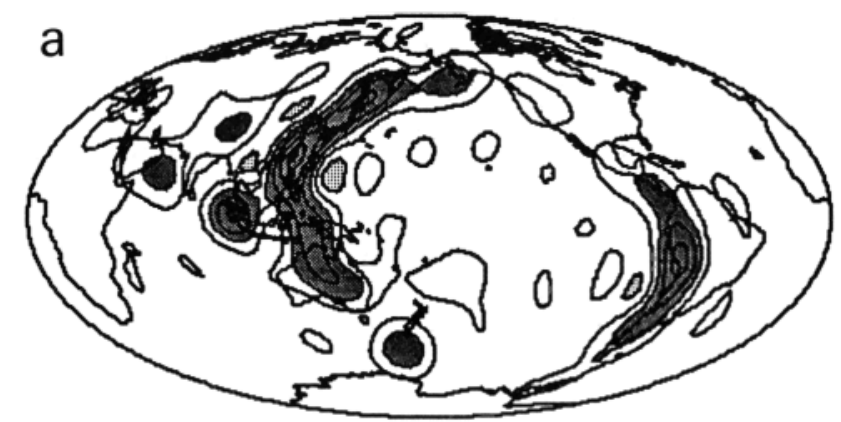

SLABS (DEPTH $1000 \mathrm{KM}$, DEGREES 1-3)

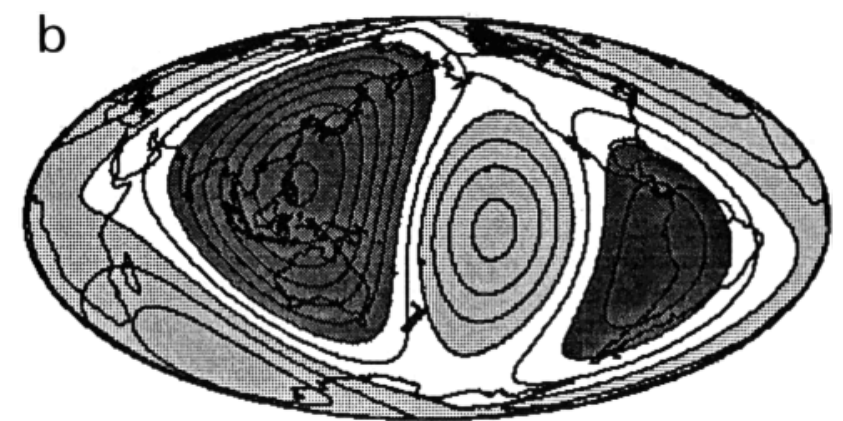

SH425.2 (DEPTH $1000 \mathrm{KM}$, DEGREES 1-3)

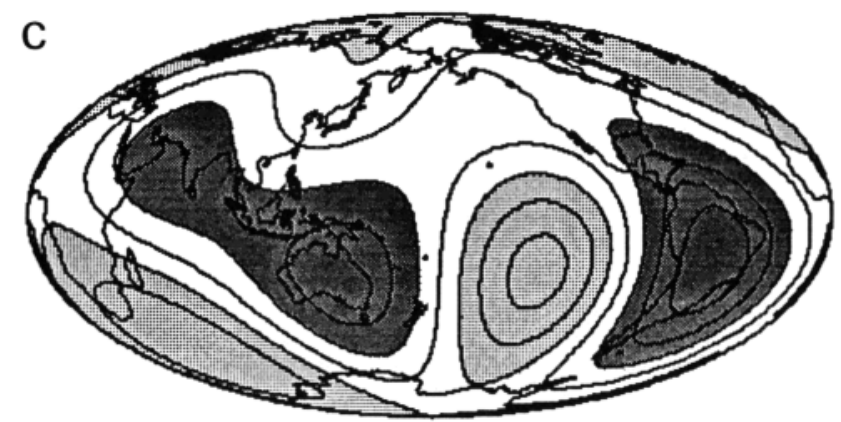

Fig. 6. Same as in Figure 5 but at the depth of $1000 \mathrm{~km}$. The level lines in Figures $6 \mathrm{~b}$ and $6 \mathrm{c}$ are $2.0 \mathrm{~kg} \mathrm{~m}^{-3}$ apart. The slab distribution and the tomography have the same sectoral pattern.

more sophisticated inversions to be around 10 [Mitrovica and Peltier, 1992]. Larger viscosity contrasts up to a factor of 100 have been proposed from analysis of far-field oceanic island data on sea level changes [Nakada and Lambeck, 1989]. From models of long-wavelength geoid anomalies using seismic tomography, a ratio of 30-50 has been deduced from twolayer models [Ricard and Vigny, 1989]. This value roughly agrees with that obtained by averaging three-layer models [Hager and Richards, 1989] or continuons models [Forte, 1992].

From the slab velocity decrease of 3-4 determined above, we infer that the viscosity increase should be between this value and its exponential, say between 3 and 60 . As a first experiment we choose $\eta_{l}=40, \eta_{i t h}=10$ and a factor of velocity reduction $s=4$ to compute the synthetic geoid. This synthetic geoid is found to have a strikingly good correlation with the observed one. The fit may be measured in terms of variance reduction $V_{r}$, which is defined by

$$
V_{r}=1-\left(\frac{A_{R}}{A_{N}}\right)^{2},
$$

where $A_{R}$ is the amplitude of the residual geoid (the difference between observed and computed geoids) and $A_{N}$ is the amplitude of the real geoid. Including all degrees up to $l=15$, our "first guess" model achieves a variance reduction of $70 \%$.

To clarify this result and to estimate the uncertainties in chosing our three parameters, namely, s, $\eta_{\text {ith }}$, and $\eta_{l}$, we compute the total correlation between the synthetic and the observed geoid when only one of these parameters is varied, with the other ones kept constant. Since the total correlation mainly reflects the correlation at degrees where the amplitudes are large, i.e., at degrees 2 and 3 for the geoid, we also compute the total correlation between synthetic and observed free-air gravity anomalies. The expansion in spherical harmonics of free-air gravity anomalies can be deduced from that of the geoid by multiplying the geoid coefficients by $(l-1) / a$, where $a$ is Earth's radius. This multiplication leads to a signal having a much flatter spectrum than that of the geoid. A high correlation between predicted and observed free-air gravity demonstrates that our model is also satisfactory at shorter wavelengths. 

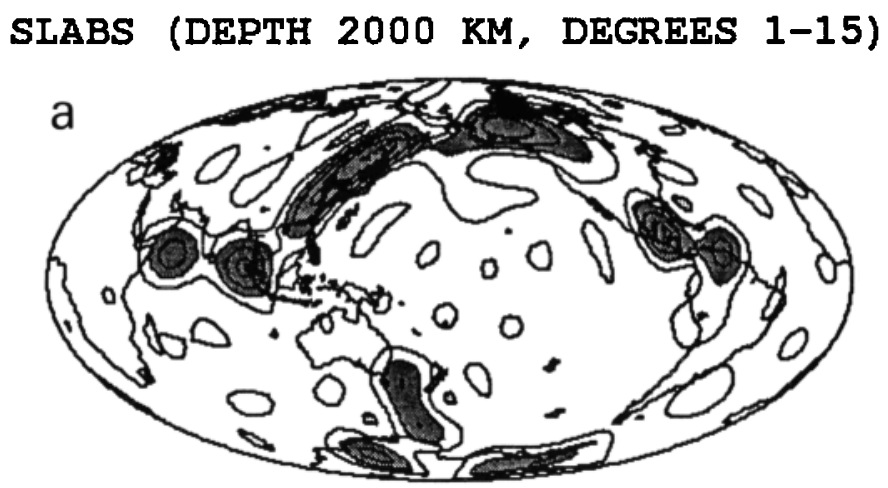

\section{SLABS (DEPTH $2000 \mathrm{KM}$, DEGREES 1-3)}
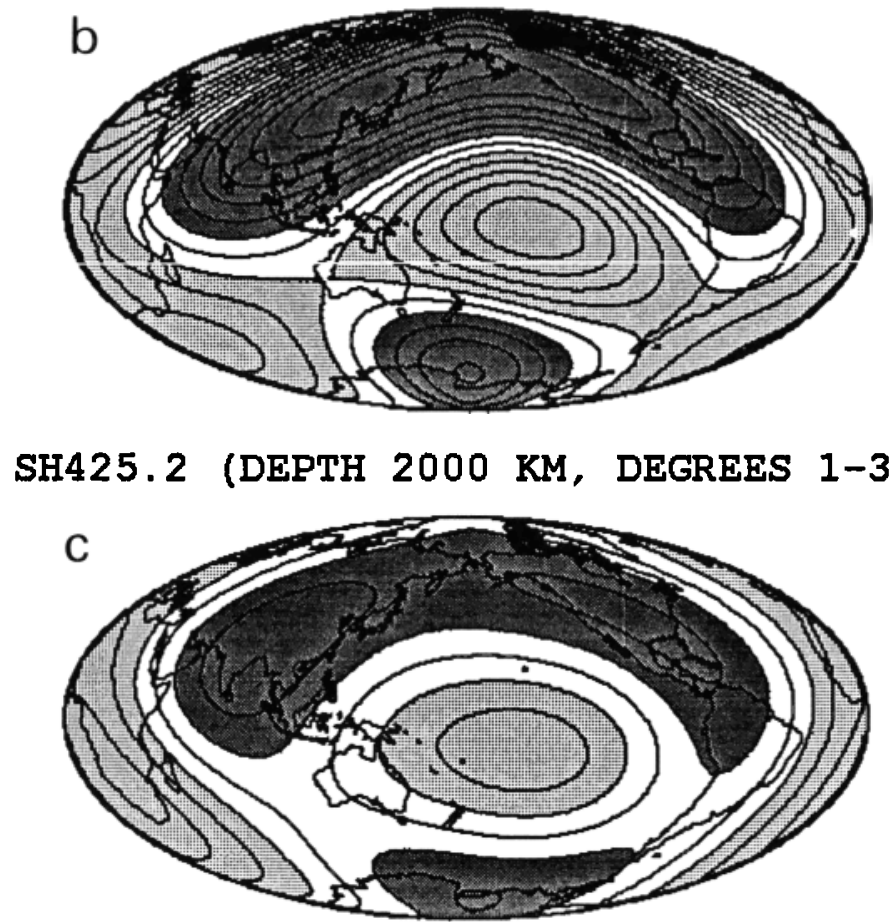

Fig. 7. Same as in Figure 6 but at the depth of $2000 \mathrm{~km}$. The level lines in Figures $7 \mathrm{~b}$ and $7 \mathrm{c}$ are $2.0 \mathrm{~kg} \mathrm{~m}^{-3}$ apart. The slab distribution and the tomography have the same zonal pattem.

Figure 8 shows the correlations including all degrees up to $l=8$ between predicted and observed geoid (open and solid squares) and free-air gravity (diamonds). The curves without $C_{21}, S_{21}$ components (open squares) will be discussed later. The lower mantle viscosity, the lithospheric viscosity, and the factor of velocity reduction at $670-\mathrm{km}$ depth are varied in the top, middle, and bottom panels, respectively. Except for the parameter which is varied, the other parameters are $\eta_{l}=40, \eta_{l i t h}=10$, and $s=4$. In each panel, clear correlation maxima are found reaching 0.84 for the geoid (with $C_{21}, S_{21}$ ) and 0.72 for the free-air gravity. If we specify that satisfactory models lead to a computed versus observed geoid correlation larger than 0.6 , we can specify the acceptable range of our model parameters. The viscosity increase at $670-\mathrm{km}$ depth is between 25 and 60 . The lithospheric viscosity is at most 40 times that of the upper mantle. The best fits obtained in varying $s$ are obtained for a velocity reduction by a factor between 3 and 8 . This is also the interval in which our slab model is highly correlated with tomography.
We have tried to optimize the choice of the three coefficients, $\eta_{l}, \eta_{l i t h}$, and $s$. The set of parameters obtained after a simple trial and error procedure is $\eta=37, \eta_{i i t h}=11$, and $s=4.4$. This set leads to a global correlation between the observed and computed geoid with $C_{21}, S_{21}$ of 0.88 . Between the observed and computed free-air gravity, the correlation decreases to 0.74 , a value which is still highly satisfactory since the total effective degrees of freedom is larger due to the flatter gravity spectrum. The best variance reduction in the geoid signal is obtained when the slabs subducting with a $10 \mathrm{~cm} / \mathrm{yr}$ velocity have an excess density of $66 \mathrm{~kg} / \mathrm{m}^{3}$ a value which is close to the a-priori value of $80 \mathrm{~kg} / \mathrm{m}^{3}$ of equation (1). With such a slab excess density, the variance reduction is $78 \%$ of the geoid and reaches $84 \%$ when $C_{21}, S_{21}$ are set to zero.

The observed geoid, the best fit computed geoids with and without $C_{21}, S_{21}$ terms, and the residual geoid with and without $C_{21}, S_{21}$ terms are depicted in Figure 9. Our very simple model has only two important parameters, the viscosity ratio and the slab velocity decrease at $670 \mathrm{~km}$, and these 
COMP. VS. OBS. GEOID

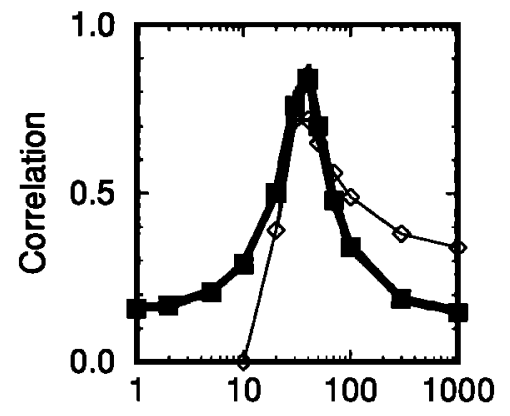

Normalized lower mantle viscosity
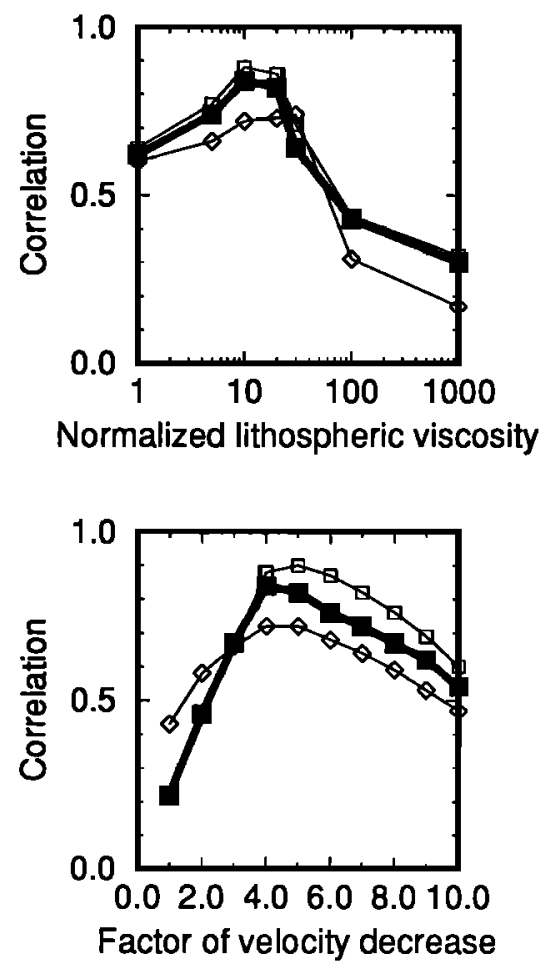

Fig. 8. Global correlations between observed and computed geoid (squares) and observed and computed free air gravity (diamonds). For the open squares, the components of degree 2 order 1 are excluded. For the solid squares, they have been included in the correlation. The lower mantle viscosity, the lithospheric viscosity, and the factor of velocity decrease at $670 \mathrm{~km}$ are varied in the top, middle, and bottom panel, respectively. Except for the parameter which is varied, the other parameters are $\eta=40, \eta_{\text {ith }}=10$, $s=4$.

two parameters are not entirely independent. However, our model gives a better fit to the geoid than can be obtained using seismic tomography and a much larger number of free model parameters [e.g., Forte, 1992]. Figure 9d shows that our residual geoid has a relative maximum over most ridges: the Indian Ocean triple junction, the West Pacific ridge, and the Atlantic ridge. We have computed in Figure 10 the average value of the residual geoid as a function of oceanic lithospheric age. The decrease of geoid height with age up to $60 \mathrm{Ma}$ is in agreement with predictions from models of oceanic cooling [Sandwell and Schubert, 1980]. Between 120 and $180 \mathrm{Ma}$, the residual geoid over the oldest part of the
Pacific lithosphere corresponds to a geoid heigh. Using the values of Figure 10 but ascribing a geoid height of $-5 \mathrm{~m}$ between 120 and $180 \mathrm{Ma}$, we have constructed an age dependent geoid. This geoid only reduces by $7 \%$ the variance of the residual geoid and by $1 \%$ the variance of the observed geoid. This confirms the weak contribution of near surface density anomalies to the geoid.

The degree-by-degree correlations between our computed geoid and the observed geoid are shown in Figure 11 curve a. A comparison of the two spectra is shown in Figure 11, curve $b$. The correlations are higher than the $95 \%$ confidence level for the first 8 degrees, and degrees 10 and 11 exceed the $90 \%$ level. For $l=2$, an open square labeled a shows the correlation obtained when the $C_{21}, S_{21}$ terms are set to zero. The spectrum we predict has an amplitude that is slightly too high for degrees greater than 5 . Some phenomena which are not taken into account in our model could somewhat screen the short wavelengths: The elasticity of the lithosphere or the thermal diffusion that increases the slab thickness, for example. However, a better description of slab densities and/or the addition of lateral density variations in the lithosphere may explain this discrepancy.

\section{Rotational Dynamic's and True Polar Wander}

In a rotating Earth, there is no $C_{21}$ or $S_{21}$ geoid, because the rotation axis is always a principal axis of inertia. In most previous work on modeling the geoid (including that of M. Richards), the dynamic topograpliy is computed in a geographical reference frame with one axis coincident with Earth's rotation pole but without consideration of the effects of rotation. Such an approach assumes that any modeled $C_{21}$ or $S_{21}$ geoid components are the result of modeling error, implicitly assuming that Earth's rotational figure adjusts instantaneously to any internal $C_{21}$ and $S_{21}$ heterogeneity. However, it is clear that this adjustment cannot be instantaneous [Sabadini and Yuen, 1985; Ricard and Sabadini, 1990], and there are two alternatives for the interpretation of model $C_{21}$ and $S_{21}$ terms. In order to understand these alternatives, it is necessary to consider Earth's response to $C_{21}$ and $S_{21}$ loading.

Let us imagine that we suddenly impose a $C_{21}, S_{21}$ gravity potential on an Earth rotating about its geographical pole $O$ (Figure 12). Our model for the geoid predicts a geoid minimum at degree 2 (a principal inertia axis) located at $P$, which is $20^{\circ}$ from the present pole of rotation and at a longitude $130^{\circ} \mathrm{W}$ (over Alaska). However, the position of the inertia axis at $P$ does not take into account the Earth's huge equatorial bulge, which has an amplitude of $21 \mathrm{~km}$. This bulge results from rotational flattening, and cannot instantaneously adjust to the 'new' rotation axis. The actual instantaneous response of the Earth is to induce a Chandler wobble about an intermediate position, $Q$, until the bulge relaxes. This point $Q$ is at an angle $c$ from the original axis $O$ given by

$$
\epsilon=\left(I_{z x}^{2}+I_{z y}^{2}\right)^{1 / 2} /(C-A),
$$

where $I_{z i}$ are the nondiagonal inertia components in the geographical frame and $C-A$ is the difference between the equatorial and polar hydrostatic inertia values. The off diagonal inertia tensor terms are related to the geoid coefficients at degree 2 by

$$
I_{z x}=M a^{2}(5 / 3)^{1 / 2} C_{21}
$$




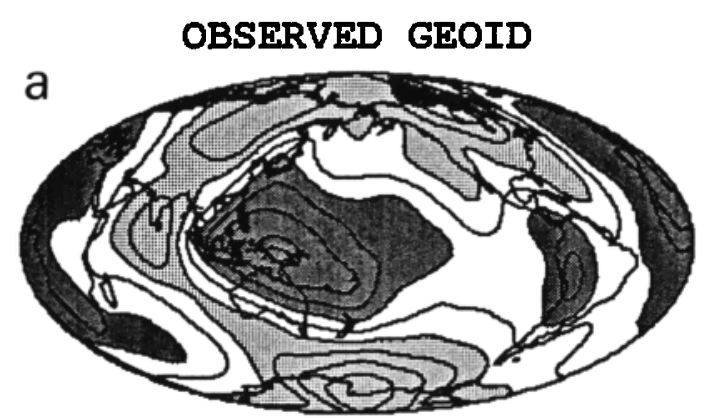

COMPUTED GEOID WITHOUT C21 S21

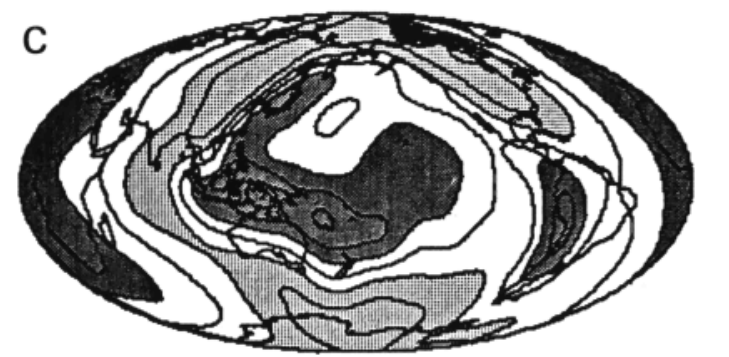

COMPUTED GEOID WITH C21 S21

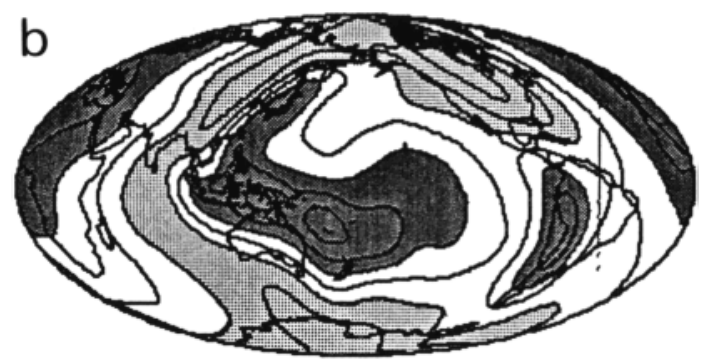

RESIDUAL GEOID

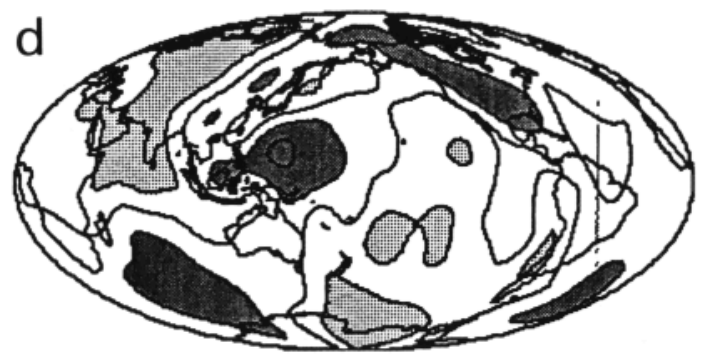

contour level: $25 \mathrm{~m}$

Fig. 9. (a) Observed, (b) and (c) computed, and (d) residual geoid. In the four maps, the level lines are $25 \mathrm{~m}$ apart. The maxima are shaded with dark grey; the ninima are shaded with light grey. In Figure $9 \mathrm{c}$ the $C_{21}, S_{21}$ components are zero. Figure 9d corresponds to the difference between Figures 9a and 9c.

and

$$
I_{z y}=M a^{2}(5 / 3)^{1 / 2} S_{21}
$$

where $M$ is the Earth's mass and $a$ the Earth's radius. The angle $\epsilon$ between $O$ and $Q$ is expected to be small, because the rotational bulge (a $C_{20}$ term) is hundreds of times larger than the $C_{21}$ and $S_{21}$ terms that arise from internal heterogeneity, a small shift in the rotation axis results in a large effective change in the off diagonal inertia tensor terms. In our model the predicted $C_{21}, S_{21}$ terms imply a position for $Q$ only $6 \mathrm{~km}$ from the present pole. The Chandler wobble itself is damped out after a few hundred years, so that the "near instantaneous" response of Earth is to shift its rotation axis to $Q$. Since $Q$ is only $6 \mathrm{~km}$ from the geographical pole $O$, the new rotational reference frame is not significantly different from the original geographical reference frame. The small shift in the rotation axis from $O$ to $Q$ will just cancel the degree $C_{21}$ and $S_{21}$ geoid terms, and there will be no observed $C_{21}$ or $S_{21}$ geoid.

In time, the rotational bulge of Earth will relax toward its "final" state, with flattening about a pole at position $P$. This state is reached by true polar wander (TPW) governed by internal viscous adjustment to the centripetal potential. This adjustment may require millions of years, depending upon the viscosity structure of the mantle [Ricard et al., 1992, 1993]. In the final state, a perfect geoid model should predict no $C_{21}, S_{21}$ terms (in the new rotational reference frame), and most previous geoid models based on seismic tomography have assumed that this viscous adjustment is complete. However, the relaxation time for Earth's rotational bulge is unknown. Evidence for a long relaxation time has been published by Spada et al. [1992], who argue that rearrangements in subduction would have induced far greater rates of TPW than have been observed in the Cenozoic un- less the average viscosity of the mantle were substantially higher than $10^{21} \mathrm{~Pa}$ s. The TPW velocity components $\dot{m}_{x}$ and $\dot{m}_{y}$ are given by

$$
\dot{m}_{x}=\frac{I_{z x}}{(C-A) \tau},
$$

and

$$
\dot{m}_{y}=\frac{I_{z y}}{(C-A) \tau},
$$

where $\tau$ is a time constant somewhat similar to the time constant entering the post glacial rebound problem. This

\section{AVERAGED GEOID VS. AGE}

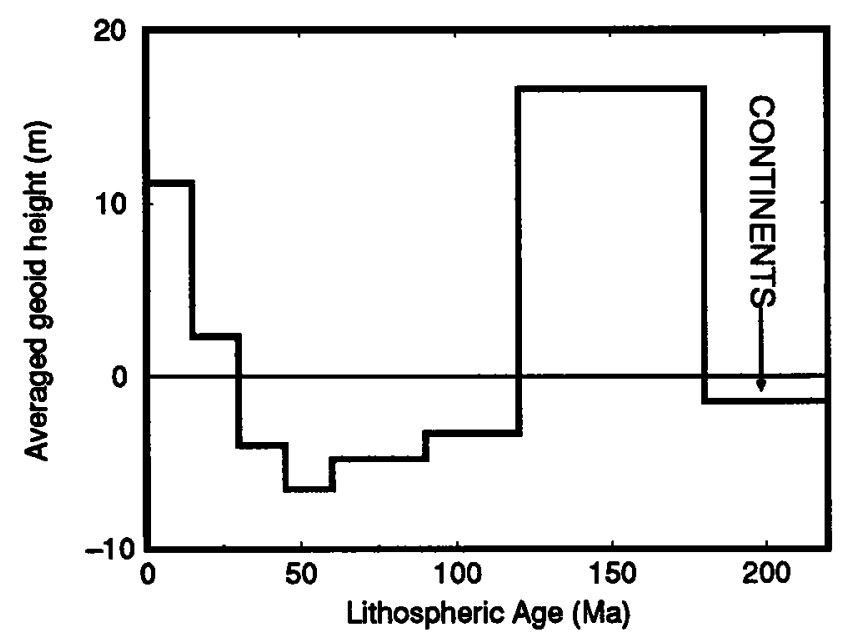

Fig. 10. Averaged residual geoid as a function of lithospheric age and tectonic setting. The geoid height decreases by about $15 \mathrm{~m}$ between young and old oceanic lithosphere. 


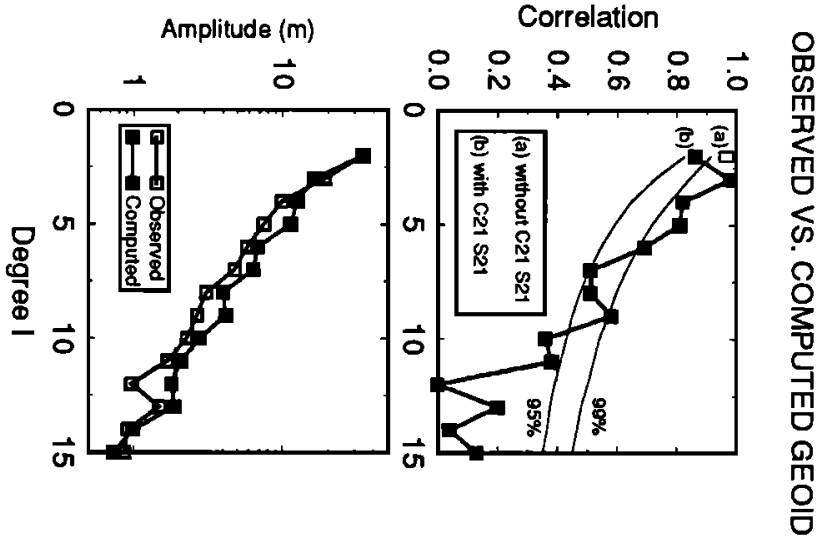

Fig. 11. The top panel depicts the correlation between the computed and the observed geoid. Our results are above the $95 \%$ confidence level for the first 9 degrees. For $l=2$ the correlation has been computed without (curve a) and with (curve b) $C_{21}$, $S_{21}$ components. The amplitude spectra of the computed (solid squares) and observed (open squares) geoids are plotted in the bottom panel.

time constant arises from the relaxation of the Earth under tidal forcing instead of surface loading as for the post glacial rebound problem. For our mantle viscosity profile and assuming an upper mantle viscosity of $2 \times 10^{21} \mathrm{~Pa} \mathrm{~s}, \tau$ should be around 60,000 yrs [see Ricard et al., 1993], and the TPW induced by our model should move the pole toward $P$ with a velocity of $2.7^{\circ} / \mathrm{m} . \mathrm{y}$. in the direction $130^{\circ} \mathrm{W}$. This true polar wander is significantly greater than the observed rate of true polar wander for the Cenozoic which is not more than about $1 \% \mathrm{~m} . \mathrm{y}$. in the direction $50^{\circ} \mathrm{W}$ [Besse and Courtillot, 1991].

With the forgoing discussion as background, we can now specify two alternative interpretations of the $C_{21}, S_{21}$ terms in our geoid model. The first is that the Eartl's rotational bulge adjusts rapidly compared to the timescale for convection, and our model is simply in error. This case would follow assumptions implicit in previous work by, e.g., Hager and Richards [1989] and Forte and Peltier [1991], and the modeled $C_{21}, S_{21}$ terms should be kept in performing correlations between the observed and modeled geoid.

The second alternative is that the relaxation time for the bulge is longer than that calculated above, implying that the absolute viscosity of the upper mantle is at least a factor of 3 higher than that estimated from glacial rebound studies, thus reducing the rate of TPW to only about $1 \% \mathrm{~m} . \mathrm{y}$. In this case, one could not expect the modeled $C_{21}, S_{21}$ geoid terms to be zero, and they should not be included in the correlation between observed and modeled geoid.

In light of these uncertainties, the proper interpretation for our model $C_{21}, S_{21}$ terms is not obvious. Accordingly, we have included in Figures 8 and 11 a set of curves that give correlations between the observed and modeled geoid in which the $C_{21}, S_{21}$ terms have been set to zero. Of course, this improves the correlations considerably, and our best fitting model gives a variance reduction in the geoid of $84 \%$.

It seems that a simple three-layer model (lithosphere, npper mantle, lower mantle) camnot explain simmltaneously the present-day geoid and the observed TPW. We have seen that a viscosity ratio of order 40 leads to an excellent fit to the geoid but to an unacceptable TPW. On the other hand, a viscosity increase by a factor 100 at the upper-lower mantle boundary would induce a TPW of $0.4^{\circ} / \mathrm{m} . \mathrm{y}$. in the direction $70^{\circ} \mathrm{W}$, which roughly agrees with observations, but leads to a poor fit to the geoid (see Figure 8c). Further work is clearly needed to address the problem of TPW in the ('enozoic. The trajectory of the pole with time is governed by a complex nonlinear Liouville equation; it may be too great an oversimplification to use equations (8) and (9) over a period where the geoid and the inertia tensor are variable.

\section{Plate Motion And Dynamic: Topography}

From the density distribution inferred from slabs and with the viscosity profile used to predict the geoid we can compute mantle flow velocities and the surface dynamic topography. With radial models, only the poloidal velocity is excited whereas the toroidal velocity is zero. As slabs are known to be a major driving force of plate motions, our model will clearly give a good fit to the observed poloidal velocity. 'Although the forces related to the thickening with age of oceanic plates (the ridge push) are missing in our modeling, correlations between computed and observed velocities are larger than the $90 \%$ confidence level for most of the 15 first degrees (Figure 13). As for the geoid, our simple geodynamic model of mantle density heterogeneity gives a better explanation for surface motions than obtained from seismic tomography.

The key to computing geoid anomalies from internal sources is to take into account the effects of the dynamically maintained topography at the surface and at the coremantle boundary. Generally, the topography at the surface has been inferred to be rather similar in pattern to the geoid [e.g., Hager and Clayton, 1989]. The observation of dynamic topography is very difficult as most of Earth's surface topography is related to crustal and lithospheric variations, not to deep inantle flow. Using seafloor topography data, Cazenave et al. [1989] suggest the existence of a dynamic topography in phase with the geoid. By contrast, using the same data, Colin and Fleitout [1990] ascribe all the observed oceanic topography to an age dependent curve and claim that the amplitude of dynamic topography is zero.

\section{POLE TRAJECTORY}

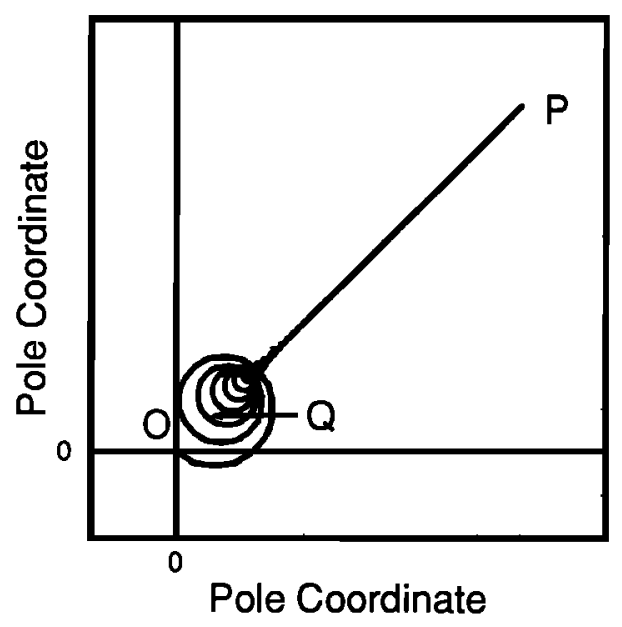

Fig. 12. Schematic diagram showing the pole trajectory in a geographical frame when the nonhydrostatic main inertia axis is suddainly moved from $O$ to $P$. The Earth starts to nutate around $\mathrm{Q}$ at the Chandler period. The amplitude of this nutation decreases very rapidly whereas its center moves slowly toward P. 


\section{OBSERVED VS. COMPUTED DIVERGENCE}

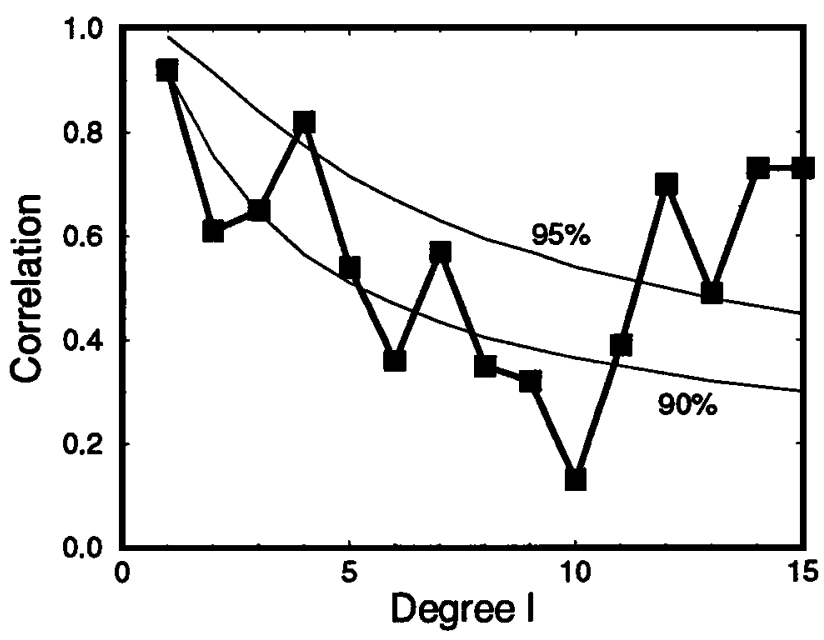

Fig. 13. Correlation between observed and computed poloidal velocity at Earth's surface.

Figure 14 shows the surface dynamic topography up to degree 15 deduced from our model. A density contrast of 2500 $\mathrm{kg} \mathrm{m}^{-3}$ appropriate to the oceans has be used worldwide to compute this topography. On continents, the topography should be reduced by $30 \%$. This topography clearly follows the subduction zones around the Pacific. Its pattern is quite different from that of the geoid. The correlation between this dynamic topography and the geoid is only -0.25 . The dynamic topography is generally rather small except along the marginal seas and active continental margins. This explains why most of the oceanic topography can be simply approximated by an age dependent curve. The fact that the dynamic topography is confined mainly to marginal seas and active margins makes it even more difficult to observe, since it may be partly filled by sediments or counterbalanced by a hotter (or wetter) upper mantle in the back-arc regions.

\section{TIME-DEPENDENT GRAVITY}

If we assume that most of the geoid is related to past subduction, we can also compute a time-dependent geoid. Instead of adding all the past slabs until the present, we can add all the slabs until some given time in the past. Our model of present-day anomalies is independent of slabs subducted $200 \mathrm{~m} . y$. ago, because this time is larger than the time needed for most slabs to sink through the mantle. In our preferred model where the slab velocities are decreased by a factor 4.4 at $670 \mathrm{~km}$ depth, this characteristic time is about $120 \mathrm{~m} . \mathrm{y}$. This means that $120 \mathrm{~m} . \mathrm{y}$. of plate motion must be known before any given time in order to compute the geoid at that time. This also means that it is reasonable to attempt to model gravity variations at least back to the beginning of the Cenozoic.

Knowledge of the past gravity field opens the possibility of addressing a large number of problems in geodynamics with new insight. To name a few: What is the "age" of the present geoid? What gravity changes and what sealevel changes can be related to mantle dynamics? How does plate motion (subduction) affect Earth's rotation? We are far from being able to answer these questions, but we can already make some remarks.

A model prediction which should be quite independent of the assumptions about the mantle heterogeneity in the early Mesozoic is the present time derivative of the geoid. Figure 15 depicts the present-day changes in geoid height predicted by our model. The fastest changes are occurring with velocities of about $4 \mathrm{~m} / \mathrm{m}$.y. The variation in Earth flattening corresponds to a decrease of $\dot{C}_{20}=-210^{-21} \mathrm{~s}^{-1}$. This change is much slower than what is estimated from the secular acceleration of the node of the LACiEOS satellite. This observation also corresponds to a decrease of flattening but of order $\dot{C}_{20}=-10^{-18} \mathrm{~s}^{-1}$ [Yoder et al., 1983]. This present-day deformation is likely the consequence of the ongoing isostatic adjustment to the removal of the ice load in Late Pleistocene time [e.g., Sabadini and Peltier, 1981]. This fast decrease in flattening will only go on for a few more thousand years until complete isostatic equilib-

\section{DYNAMIC TOPOGRAPHY}

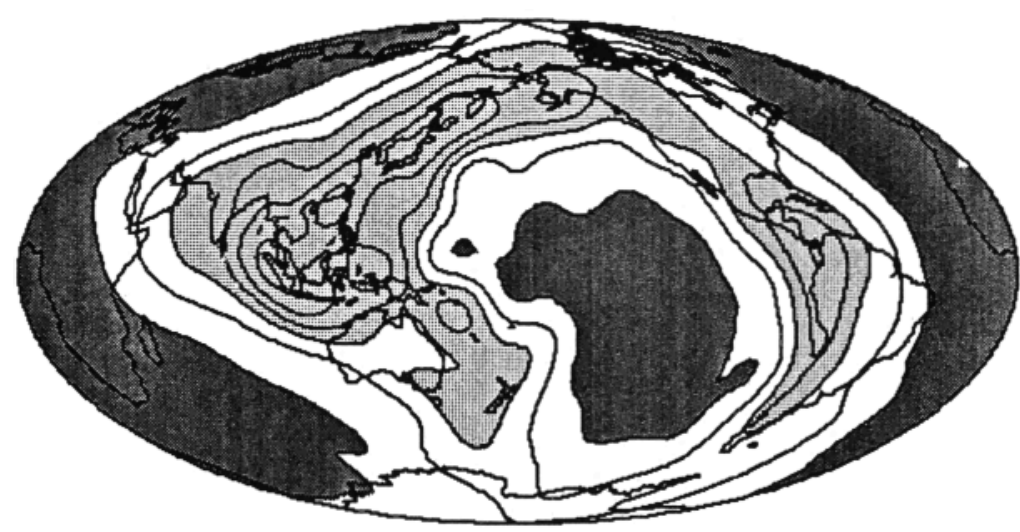

contour interval: $500 \mathrm{~m}$

Fig. 14. Dynamic topography induced by the slab distribution. A depression reaching more than $2 \mathrm{~km}$ under water tracks the westem Pacific subduction zones. The dynanic topography is generally very weak in the ocean basins. 


\section{GEOID VARIATIONS}

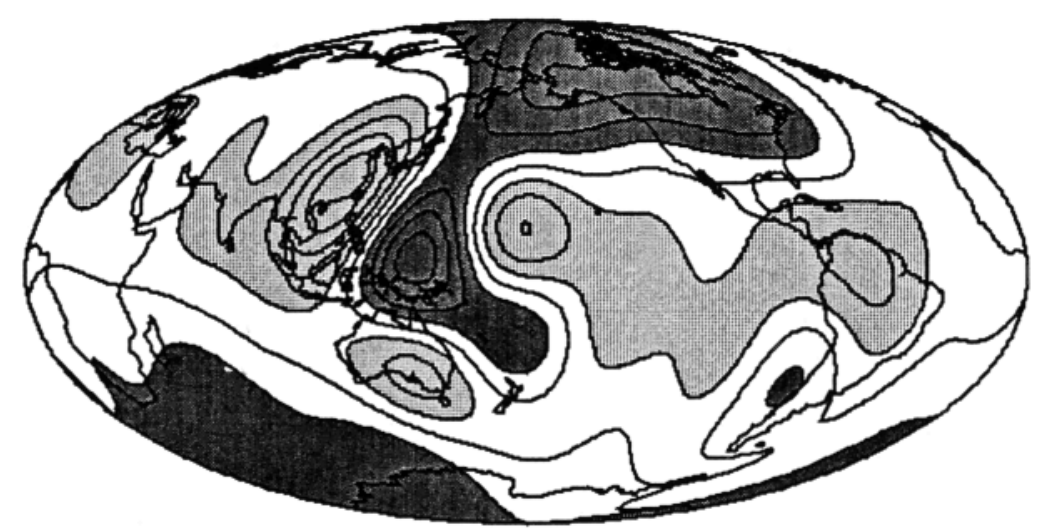

contour interval: $1 \mathrm{~m} / \mathrm{Myr}$

Fig. 15. Present-day geoid variations computed by our model. The level lines are $1 \mathrm{~m} / \mathrm{m}$.y. apart. The dark shading shows the regions where a geoid rise is predicted. A decrease in the polar flattening is predicted.

rium is achieved, whereas our slow secular change may go, on for million of years.

Even though the gravity changes due to mantle mass redistribution are negligible compared to the changes due to postglacial rebound, their amplitudes will be important for long time periods. Since the absolute amplitude for the observed geoid undulations is around $\pm 100 \mathrm{~m}, 30 \mathrm{~m} . \mathrm{y}$. of changes with velocities of $4 \mathrm{~m} / \mathrm{m}$.y. may completely modify the geoid shape. To be more precise, we compute tlie autocorrelation with time of our computed geoid. Figure 16 depicts this autocorrelation function. To illustrate the possible effects of missing the oldest slabs, we assume two possible starting structures for the mantle. The curve labeled $200 \mathrm{Ma}$ assumes that the mantle had no density heterogeneities $200 \mathrm{~m} . \mathrm{y}$. ago. In the curve labeled $300 \mathrm{Ma}$, we start to add slabs $300 \mathrm{~m} . \mathrm{y}$. ago, assuming that during the first $100 \mathrm{~m} . \mathrm{y}$. subduction was the same as that estimated $200 \mathrm{~m} . y$. ago. This model thus assumes that 200 m.y. ago the Mesozoic slabs that surrounded Pangea were sinking through the whole mantle. The difference between the two curves is only visible earlier than $50 \mathrm{Ma}$, when the influence of Early Mesozoic slabs becomes important. The two curves agree that the characteristic age of the presentday geoid, given by the time at which the autocorrelation is 0.5 , is about $50 \mathrm{Ma}$. This argues against the idea that the geoid varies with a much slower time constant than the surface tectonic pattern [Anderson, 1982; Le Pichon and Huchon, 1984].

Our model could in principle address the problem of sealevel variations through time. These variations are related to changes in the geoid and the dynamic topography. A comparison with observations would be a very important test for geodynamic models [Gurnis, 1990]. Sealevel variations are geologically recorded in sediments at the continental margins. The knowledge of continent positions and of oceanic seafloor topography through time must be included in our model to make a good comparison with the data. We have not yet tried to perform this exercise. On the edges of a drifting continent, such as the North and South American plates, sealevel may vary little since both the geoid undula- tion and induced dynamic topography are carried along with the plate. However, when subduction stops in our model, uplift occurs while the old slab sinks into the mantle. Such a mechanism qualitatively agrees with the tectonic history of the western United States, when Farallon plate subduction ended and when the San Andreas transform system started [Atwater, 1970; Bird and Baumgardner, 1981]. The density excess of our slabs corresponds to some $3.5 \mathrm{~km}$ of oceanic topography decrease with age under sea water. It only corresponds by isostasy to $2.5 \mathrm{~km}$ under continents. This is the order of magnitude of the change in topography predicted by our model at the end or at the beginning of an episode of subduction.

\section{Discussion}

Mantle convection is often perceived as a phenomenon that occurs "beneath the plates" and deep mantle struc-

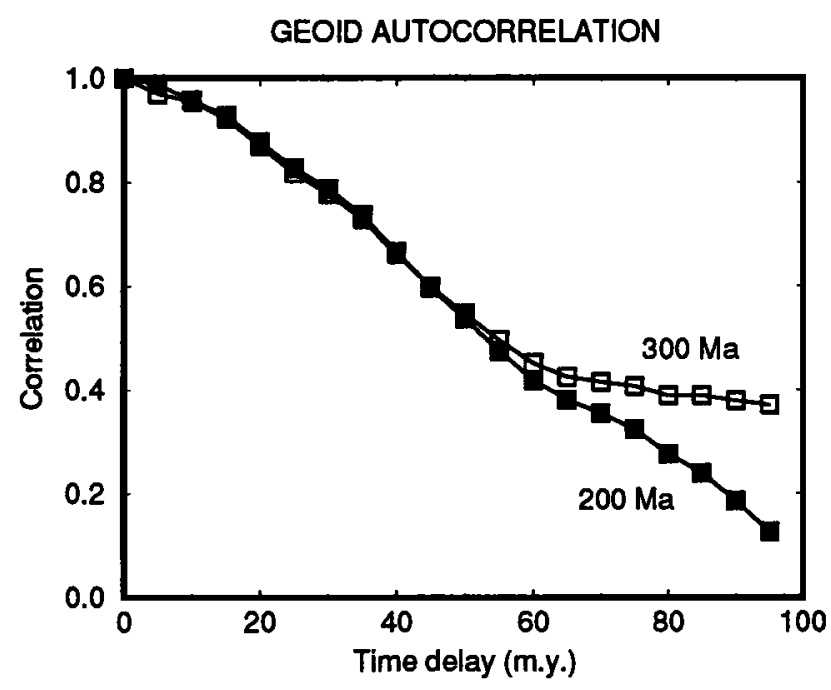

Fig. 16. Geoid antocorrelation with time. For the curve labeled $200 \mathrm{Ma}$, we started with a homogeneous mantle at $200 \mathrm{Ma}$. The oldest stage of our plate motion compilation is supposed to have started at $300 \mathrm{Ma}$ in the other curve. Both curves predict a geoid age of about $50 \mathrm{Ma}$. 
ture, away from the immediate vicinity of subduction zones, is often considered to be rather independent of surface tectonics. The results of this study suggest quite the opposite. The clearest signals of mantle heterogeneity, nancly the geoid and horizontal variations in seismic velocity, are explained as well as could be reasonably expected by a simple density heterogeneity model based on the subduction of oceanic lithosphere. The relatively weak relationship between present-day plate tectonics and large-scale heterogeneity in the deep mantle is a reflection of modest but significant changes in the pattern of subduction through recent Earth history. Accounting for "fossil" slabs, such as the Farallon plate beneath North America, erases any obvious discrepancy between mantle structure and the history of plate motions.

We believe that the success of our model derives from just a few important factors:

1. There exists an accurate record of plate motions (subduction) for what is apparently an adequate period of time to represent at least one inantle transit time.

2. Mantle dynamics is dominated by the sinking of oceanic lithosphere which represents the upper boundary layer of a primarily internally heated convecting system.

3. Upwelling mantle plumes transport a relatively small amount of heat through what appear to be rather confined, axisymmetric structures which probably contribute little to the large-scale mantle heterogeneity structure.

4. A relatively high viscosity lower mantle may allow for a prolonged spatial "memory" of past subduction, as well as providing a relatively fixed hotspot reference frame for describing the history of plate motions.

Mantle dynamics is probably more complicated than this but perhaps not by much on the large scale. The primary area of difficulty we have avoided is that of the dynamics of the mantle transition zone. We have considered only the possibility of a viscosity contrast at $670 \mathrm{~km}$, and we have so far ignored the effects of phase transformations and of a possible chemical density increase with depth. The simplest alternative model is that of slabs piling up on an impenetrable barrier at $670 \mathrm{~km}$. We have tried this, and it does not produce a geoid that is correlated with that observed. Of course, in this case we cannot model lower mantle heterogeneity. Clearly, a more sophisticated model, with thermal coupling across an internal boundary layer or perhaps with intermittent layered/whole mantle flow due to phase transitions [Machetel and Weber, 1991], is desirable, and we cannot comment at this time upon the possible merits of such models. Yet it is remarkable how well our simple, whole mantle model fits the geoid and seismic tomography, considering how few free parameters (really only one or two important ones) are involved. By contrast, recent efforts to obtain comparable fits to the geoid using seismic tomography involve many mantle viscosity layers $(\sim 10)$, as well as adjustable parameters for converting seismic velocity variations to density variations [Forte, 1992]. In that sense, our model provides a more "robust" fit to both the observed geoid and gravity field.

Some intriguing questions arise from our comparisons with seismic tomography. First, the slab density provides a good fit to the degree 2 geoid, including the $C_{20}$ term which has not generally been fit well in the past using seismic tomography. To illustrate this point, Figure 17 shows a scatter plot of observed degree two geoid components, $C_{20}, C_{21}$,
DEGREE 2 GEOID

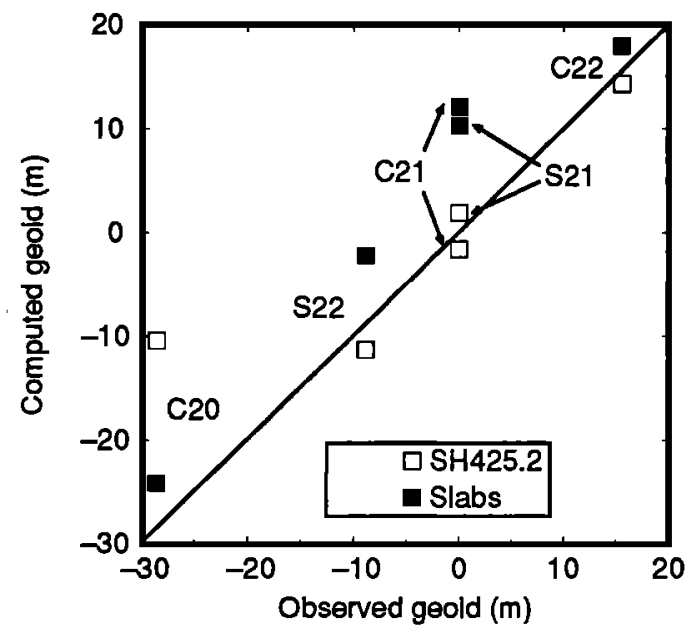

Fig. 17. Scatter plot of the computed versus observed geoid coefficients of degree 2 . The slab density model (solid squares) predicts a coefficient $C_{20}$ close to that observed. The tomographic model (open squares) predicts a too small flattening.

$S_{21}, C_{22}$, and $S_{22}$, versus those computed from seismic tomography (solid squares) and those computed from our slab density model (open squares). The two sets of synthetic geoid coefficients have been computed using the same viscosity profile. A somewhat better fit to the observations could have been obtained from SH425.2 using a different viscosity profile but always with a $C_{20}$ amplitude that is too small. This suggests the possibility of error or inaccuracy in the seismic ellipticity correction, which is very large compared to the travel time delay signal due to mantle heterogeneity for this harmonic component. The amplitude of $C_{21}, S_{21}$ components cannot be directly compared to geoid observations but are probably more relevant to the problem of TPW though Cenozoic, a problem that goes beyond the goal of this paper. Another question arises with regard to the upper mantle amplitude discrepancy between between the seismic models and our slab density model. One longrecognized possibility is that the presence of partial melt in the upper mantle, particularly in back-arc regions and beneath spreading ridges and hotspots, causes large shear wave velocity variations that do not necessarily represent large density contrasts. Another obvious influence is the possible presence of deep continental roots [Jordan, 1978], which may also produce large variations uncorrelated or even anticorrelated with density variations. Another possibility is that most tomography models are mapping into seismic velocity heterogeneity what is actually seismic anisotropy [Montagner and Tanimoto, 1991] or seismic attenuation [Romanowicz, 1990] in the upper mantle.

We note that subducted slabs are infinitely thin in our model, yet they are able to explain global seismic tomography and the geoid, both of which reflect only longwavelength mantle structure. This follows from the very non-random distribution of subduction zones over the past 200 m.y., i.e., the Pacific "ring of fire". Subducted slabs, which are initially only $\sim 100 \mathrm{~km}$ thick, probably suffer little thermal equilibration at large length scales, while they sink through the mantle. Therefore, our model predicts that seismic tomography should find sharper high velocity structures 
in the mantle as inversion techniques and digital seismic data improve. An interesting exercise would be to perform a synthetic mantle tomography experiment on our slab density model and to compare the resulting image with those obtained using seismic data. This has already been performed but with upper mantle slabs only [Snieder et al., 1991]. The results suggest that small-scale features can indeed produce normal mode frequency shifts similar to what is obtained from global tomographic inversions.

The model we have developed suggests that an appropriate mantle transit time (the time for a slab to sink to the core-mantle boundary) is of order $100 \mathrm{~m} . \mathrm{y}$., with a correlation time of about $50 \mathrm{~m} . \mathrm{y}$. being the interval required for a significant change in the geoid or global dynamic topography. It is interesting to recall that the late Mesozoic ( $\sim 70$ $120 \mathrm{Ma}$ ) was a time of very rapid plate motion, with global spreading rates as much as 2 times higher than present-day values [Engebretson et al., 1992]. This suggests not only a strong episodicity in plate motions but also episodicity in the creation of deep mantle heterogeneity. For this reason, most of the lower mantle structure in our model is "Mesozoic" in origin.

An important implication of the apparent success of our model is that we may now consider modeling the history of mantle heterogeneity. This means that we could also model the history of mantle derived tractions acting on the plates, global "eustatic" sea level variations, and variations in the Earth's rotation. The preliminary calculations of gravity variations that we have presented in this paper are intended mainly to be illustrative, and this is an exciting area for future research.

Acknowledgment. This work was partly supported by the INSU-DBT (Dynamique et Bilan de la terre) program.

\section{REFERENC:ES}

Anderson, D. L., Hotspots, polar wander, Mesozoic convection and the geoid, Nature, 2.97, 391-393, 1982.

Anderson, O. L., E. Sclireiber, R. C., Lieberman, and N. Soga, Some elastic constant data on minerals relevant to geophysics, Rev. Geophys., 6, 491-524, 1968.

Atwater, T., Implications of plate tectonics for the Cenozoic tectonic evolution of western North America, Geol. Soc. Am. Bull., 81, 3513-3535, 1970.

Besse, J., and V. Courtillot, Revised and synthetic apparent polar wander paths of the African, Eurasian, North American, and India plates and true polar wander since $200 \mathrm{Ma}, J$. Geophys. Res., 96, 4029-4050, 1991.

Bird, P., and J. Baumgardner, Steady propagation of delamination events, J. Geophys. Res., 86, 4891-4903, 1981.

Bunge, H. P., and M. A. Richards, The backward problem of plate tectonics and mantle convection, (abstract), Eos Trans. $A G U$, 73 (14), Spring Meeting suppl., 281, 1992.

Cadek, O., Y. Ricard, Z. Martinec, and C. Matyska, Comparison between Newtonian and non-Newtonian flow driven by internal loads, Geophys. J. Int., 112, 103-114, 1993.

Cazenave, A., A. Souriau, and K. Dominh, Global coupling of Earth surface topography witl hotspots, geoid and mantle heterogeneities, Nature, \$40, 54-57, 1989.

Chase, C. G., Subduction, the geoid, and lower mantle convection, Nature, 282, 464-468, 1979.

Chase, C. G., and D. R. Sprowl, The modern geoid and ancient plate boundaries, Earth Planet. Sci. Lett., 48, 15-22, 1983.

Chopelas, A., and R. Boelher, Thermal expansion measurements at very ligh pressure, systematics and a case for a chemically homogeneous mantle, Geophys. Res. Lett., 16, 1347-1350, 1989.

Colin, P., and L. Fleitout, Topography of the ocean floor: thermal evolution of the lithospleere and interaction of mantle hetero- geneites with the lithosphere, Geophys. Res. Lett., 11, 1961$1964,1990$.

Davies, G. F., Ocean bathymetry and mantle convection, 2., Small-scale flow, J. Geophys. Res., 99, 10,481-10,488, 1988 a.

Davies, G. F., Role of the lithosphere in mantle convection, $J$. Geophys. Res., 93, 10,451-10,466, $1988 \mathrm{~b}$.

Davies, G. F., and M. A. Richards, Mantle convection, J. Geol., 100, 151-206, 1992.

Duncan, R. A., and M. A. Richards, Hotspots, mantle plumes, flood basalts, and true polar wander, Rev. Geophys., 29, 31$50,1991$.

Dziewonski, A. M., Mapping the lower mantle: Determination of lateral heterogeneity in $\mathrm{P}$ velocity up to degree and order $6, J$. Geophys. Res., 89, 5929-5952, 1984.

Engetbretson, D. C., A. Cox, and R. G. Gordon, Relative motions between oceanic and continental plates in the Pacific basin, Spec. Pap. Geol. Soc. Am., 206, 1-49, 1985.

Engetbretson, D. C., K. P. Kelly, and H. J. Cashman and M. A. Richards, 180 million years of subduction, GSA Today, 2, 93-95, 1992.

Forte, A. M., The kinematics and dynamics of poloidal-toroidal coupling of mantle flow (abstract), Eos Trans. AGU, 79 (14), Spring Meeting suppl., 273, 1992.

Forte, A. M., and W. R. Peltier, Plate tectonics and aspherical Earth structure: The importance of toroidal coupling, J. Geophys. Res., 92, 3645-3679, 1987.

Forte, A. M., and W. R. Peltier, Viscous flow models of global geophysical observables, 1, Forward problems,J. Geophys. Res., $96,20,131-20,159,1991$.

Forte, A. M., R. L. Woodward, A. M. Dziewonski, and W. R. Peltier, 3-D models of mantle heterogeneity derived from joint inversion of seismic and geodynamic data (abstract), Eos Trans. AGU, 73 (14), Spring Meeting suppl., 200, 1992.

Gordon, R. J., and D. M. Jurdy, Cenozoic global plate motions, J. Geophys. Res., 91, 12,389-12,406, 1986.

Grand, S. P., Tomographic inversion for shear velocity beneath the North American plate, J. Geophys. Res., 92, 14,065-14,090, 1987.

Gumis, M., Convective mixing in the Earth's mantle, Ph.D. thesis, Aust. Nat. Univ., Canberra, 1986.

Gurnis, M., Plate-mantle coupling and continental flooding, Geophys. Res. Lett., 17, 623-626, 1900.

Hager, B. H., Subducted slabs and the geoid: Constraints on mantle rheology and flow, J. Geophys. Res., 8., 6003-6016, 1984.

Hager, B. H., and R. W. Clayton, Constraints on the structure of mantle convection using seismic observations, flow models and the geoid, in Mantle Convection, edited by W. R. Peltier, Gordon and Breach, pp. 657-763, New York, 1989.

Hager, B. H., and M. A. Richards, Long-wavelength variations in the Earth's geoid: Plhysical models and dynamical implications, Philos. Trans. R. Soc. London, Ser. A, 388, 309-327, 1989.

Hager, B. H., R. W. Clayton, M. A. Richards, R. P. Comer, and $A$. M. Dziewonski, Lower mantle heterogeneity, dynamic topography, and the geoid, Nature, 313, 541-545, 1985.

Jordan, T. H., Composition and development of the continental tectosphere, Nature, 274, 544-548, 1978.

Larson, R. L., and C. (i. Chase, Late Mesozoic evolution of the western Pacific, Geol. Soc. Am. Bull., 83, 3627-3644, 1972.

Larson, R. L., and W. C. Pitman, World-wide correlation of Mesozoic magnetic anomalies and its implication, Geol. Soc. Am. Bull., 83, 3645-3662, 1972.

Le Pichon, X., and P. Huchon, Geoid, Pangea and convection, Earth Planet. Sci. Lett., 67, 123-135, 1984.

Lithgow-Bertelloni, C., M. A. Richards, Y. Ricard, R. J. $O^{\prime}$ Connell, and D. C. Engetbretson, Toroidal-poloidal partitioning of plate motjon since $120 \mathrm{Ma}$, Geophys. Res. Lett., 20, 375-378, 1993.

Machetel, P., and P. Weber, Intermittent layered convection in a normal mantle with an endothemic phase change at $670 \mathrm{~km}$, Nature, 350, 55-57, 1991

McKenzie, D. P., J. M. Roberts and N. O. Weiss, Convectjon in the Earth's mantle: Towards a numerical simulation, J. Fluid Mech., 62, 465-538, 1974.

Minster, J. B., and T. H. Jordan, Present-day plate motions, $J$. Geophys. Res., 8:, 5331-5354, 1978.

Mitrovica, J. X., and W. R. Peltier, The radial profile of mantle 
viscosity (abstract), Eos Trans. $A G U, 73(14)$, Spring Meeting suppl., 202, 1992.

Montagner, J. P., and T. Tanimoto, Chobal upper mantle tomography of seismic velocities and anisotropies, J. Geophys. Res., $96,20,337-20,351,1991$.

Morgan, W. J., Convection plumes in the lower mantle, Nature, 230, 42-43, 1971.

Nakada, M., and K. Lambeck, Late Pleistocenic and Holocene sea-level change in the Australian region and mantle rheology, Geophys. J. Int., 96, 497-517, 1989.

Peltier, W. R., and A. M. Tushingham, (ilobal sea level rise and the greenhouse effect: Might they be comected, Science, 244, 806-810, 1989.

Ricard, Y., and R. Sabadini, Rotational instabilities of the Earth induced by mantle density anomalies, Geophys. Res. Lett., I7, 627-630, 1990.

Ricard, Y., and C. Vigny, Mantle dynamics witlı induced plate tectonics, J. Geophys. Res., 94, 17,543-17,559, 1989.

Ricard, Y., L. Fleitout, and C. Froidevaux, (ieoid heights and lithospheric stresses for a dynamic Earth, Ann. Geophys., 2, 267-286, 1984.

Ricard, Y., C. Vigny, and C. Froidevaux, Mantle heterogeneities, geoid and plate motion: A Monte carlo inversion, $J$. Geophys. Res., 94, 13,739-13,754, 1989.

Ricard, Y., R. Sabadini, and G. Spada, Isostatic deformations and polar wander induced by redistribution of mass within the Earth, J. Geophys. Res., 97, 14,223-14,236, 1992.

Ricard, Y., G. Spada, and R. Sabadini, Polar wandering of a dynamic Earth, Geophys. J. Int., 11:3, 284-298, 1093.

Richards, M. A., Hotspots and the case for a high-viscosity lower mantle, in Glacial Isosiasy, Sea Level and Mantle Rheology, edited by R. Sabadini et al., pp. 571-588, Kluwer Academic, Hingliam, Mass., 1991.

Richards, M. A., and B. Hager, Effects of lateral viscosity variations on long-wavelength geoid anomalies and topography, $J$. Geophys. Res., 94, 10,299-10,313, 1989.

Richards, M. A., and D. C. Engebretson, Large-scale mantle convection and the history of subduction, Nature, $955,437-440$, 1992.

Richards, M. A., and B. H. Hager, Geoid anomaly in a dynamic Earth, J. Geophys. Res., 89, 5987-6002, 1984.

Romanowicz, B., The upper mantle degree 2: Constraints and inferences on attenuation tomography from global mantle wave measurements, J. Geophys. Res., 95, 11,051-11,071, 1990.

Sabadini, R., and W. R. Peltier, Pleistocenjc deglaciation and the Earth's rotation: Implications for mantle viscosity, Geophys. $J$.
R. Astron. Soc., 8., 553-578, 1981.

Sabadinu, R., and D. A. Yuen, Mantle stratification and long-tern polar wander, Nature, $399,373-375,1989$.

Sandwell, D., and G. Schubert, Geoid versus age for symmetric spreading ridges, J. Geophys. Res., 85, 7235-7241, 1980.

Scotese, C. R., Atlas of Phanerozoic plate tectonic reconstructions, Paleomap Proj. Tech. Rep., 36, University of Texas at Arlington, pp. 1-38, Arlington Texas, 1992.

Slater, J. G., and J. Francheteau, The implications of terrestrial heat flow observations on current tectonic and geochemical models of the crust an upper mantle of the Earth, Geophys. J. R. Astron. Soc., 20, 509-542, 1970 .

Sleep, N. H., Hotspots and mantle plumes: Some phenomenology, J. Geophys. Res., 95, 6715-6736, 1991.

Snieder, R., J. Beckers, and F. Neele, The effect of small-scale structure on normal mode frequencies and global inversions, $J$. Geophys. Res., 96, 501-515, 1991.

Spada, G., Y. Ricard, and R. Sabadini, True polar wander for a dynamic Earth, Nature, 360, 452-454, 1992.

Su, W.-J., and A. M. Dzjewonskj, Predominance of long wavelength heterogeneity in the mantle, Nature, 352, 121-126, 1991.

Tanimoto, T., Long-wavelength $S$-wave velocity structure tluroughout the mantle, Geophys. J. Int., 100, 327-336, 1990.

Yoder, C. F., J. G. Williams, J. O. Dickey, B. E. Scluutz, R. J. Eanes and B. D. Tapley, Secular variation of the Eartl's gravitational harmonics $J_{2}$ coefficient from Lageos and nontidal acceleration of the Earth rotation, Nature, 303, 757-762, 1983.

Zhang, S., and U. Christensen, The effect of lateral viscosity variations on geoid, topograplyy and plate motions induced by density anomalies in the mantel, Geophys. J. Int., in press, 1993.

Zhang, Y. S., and T. Tanimoto, Gilobal Love wave phase velocity variation and its significance to plate tectonics, Phys. Earth Planet. Inter., 66, 160-202, 1991.

Y. Le Stunff, Department of (ieology and Geophysics, University of California, Berkeley, C'A 94720.

Y. Ricard, Département Terre-Océan-Atmosphère, Ecole Normale supérieure, 24, rue Lhomond, 75231 Paris Cedex 05, France.

M. Richards and C. Lithgow-Bertelloni, Geoplyysics Program, University of Washington, Seattle, WA 98195.

(Received December 21, 1992; revised July 30, 1993; accepted August 6, 1993.) 